\title{
The temporal stability of recurrence quantification analysis attributes from chronic atrial fibrillation electrograms
}

\author{
Tiago Paggi de Almeida ${ }^{1,2 *}$, Fernando Soares Schlindwein ${ }^{3,4}$, João Salinet ${ }^{2}$, Xin $\mathrm{Li}^{5}$, \\ Gavin Shen-Wei Chu ${ }^{5,6}$, Jiun Haur Tuan ${ }^{6}$, Peter James Stafford ${ }^{6}$, G André $\mathrm{Ng}^{4,5,6}$, \\ Diogo Coutinho Soriano ${ }^{2}$ \\ ${ }^{1}$ Aeronautics Institute of Technology, São José dos Campos, SP, Brazil. \\ ${ }^{2}$ Engineering, Modelling and Applied Social Sciences Centre, Federal ABC University, São Bernardo do Campo, SP, Brazil. \\ ${ }^{3}$ Department of Engineering, University of Leicester, Leicester, United Kingdom. \\ ${ }^{4}$ National Institute for Health Research Leicester Cardiovascular Biomedical Research Centre, Glenfield Hospital, Leicester, United \\ Kingdom. \\ ${ }^{5}$ Department of Cardiovascular Sciences, University of Leicester, Leicester, United Kingdom. \\ ${ }^{6}$ University Hospitals of Leicester NHS Trust, Leicester, United Kingdom.
}

Abstract Introduction: The temporal behavior of atrial electrograms (AEGs) collected during persistent atrial fibrillation (persAF) directly affects ablative treatment outcomes. We investigated different durations of AEGs collected during persAF using recurrence quantification analysis (RQA). Methods: 797 bipolar AEGs with different durations (from $0.5 \mathrm{~s}$ to $8 \mathrm{~s}$ ) from 18 patients were investigated. Four RQA-based attributes were evaluated based on AEG durations: determinism (DET); recurrence rate (RR); laminarity (LAM); and diagonal lines' entropy (ENTR). The Spearman correlation $(\rho)$ between each duration versus $8 \mathrm{~s}$ was calculated. AEG classification was performed following the CARTO criteria (Biosense Webster) and receiving operating characteristic (ROC) curves were created for the RQA variables. Results: The RQA variables successfully discriminated the AEGs: the area under the ROC curves were as high as 0.70 for AEGs with $3.5 \mathrm{~s}$ or greater. Three types of AEGs were found using these variables: normal, fractionated and temporally unstable. The number of unstable AEGs decreased with longer AEG segments. Different AEG durations significantly affected the RQA variables $(\mathrm{P}<0.0001)$, with no statistical difference between the durations $6 \mathrm{~s}, 7 \mathrm{~s}$ and $8 \mathrm{~s}$ for DET, LAM and ENTR, and no difference between $7 \mathrm{~s}$ and $8 \mathrm{~s}$ for RR $(\mathrm{P}<0.0001)$. AEGs with $3 \mathrm{~s}$ or longer have shown $\rho \geq 80 \%$ for all variables. Conclusion: The RQA variables have been shown effective in the characterization of AEGs collected during persAF with a shorter duration than current recommendations, which motivates their use for the characterization of atrial substrate during persAF ablation.

Keywords Persistent atrial fibrillation, Fractionated electrograms, Catheter ablation, Electrophysiology mapping, Recurrence plots, Recurrence quantification analysis.

\section{Introduction}

Atrial Fibrillation (AF), defined as a supraventricular tachyarrhythmia characterized by uncoordinated atrial activation with consequent deterioration of atrial

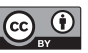

This is an Open Access article distributed under the terms of the Creative Commons Attribution License, which permits unrestricted use, distribution, and reproduction in any medium, provided the original work is properly cited.

How to cite this article: Almeida TP, Schlindwein FS, Salinet J, Li X, Chu GSW, Tuan JH, Stafford PJ, Ng GA, Soriano DC. The temporal stability of recurrence quantification analysis attributes from chronic atrial fibrillation electrograms. Res Biomed Eng. 2018; 34(4):337-349. DOI: 10.1590/2446-4740.180040.

*Corresponding author: Aeronautics Institute of Technology, Praça Marechal Eduardo Gomes, 50, Vila das Acácias, CEP 12228-900, São José dos Campos, SP, Brazil. E-mail: tiagopaggi@gmail.com Received: 28 May 2018 / Accepted: 03 December 2018 mechanical function (Calkins et al., 2017), is the most common sustained arrhythmia in clinical practice. Pulmonary vein isolation (PVI) is currently a cornerstone therapy for AF at early stages, with success rates as high as $90 \%$ for paroxysmal AF (Calkins et al., 2017; Haissaguerre et al., 1998). However, PVI has been shown insufficient for the treatment of persistent AF (persAF) due to the existence of extrapulmonary vein drivers and/or extensive structural and electric remodeling induced by sustained AF that, in turn, also participate directly in the perpetuation of the arrhythmia (Bakker and Wittkampf, 2010). Currently, it is believed that different mechanisms linked to remodeled substrate participate in persAF perpetuation. The possible mechanisms are: the rapidly discharging automatic foci (Haissaguerre et al., 1998); the meandering of multiple wavelets (Konings et al., 1994); the single reentrant circuit with fibrillatory 
conduction (Jalife et al., 2002); the conduction dissociation between epicardial and endocardial layers (Groot et al., 2016); and functional reentry resulting from rotors (Narayan et al., 2012). Patient-specific ablative strategies aiming at substrate modification adjuvant to PVI have been introduced for persAF treatment, none of which have provided a definitive solution for persAF ablative therapy (Clarnette et al., 2018) - such as posterior wall isolation, linear ablation, targeting of sites with high dominant frequency, rotational activity, areas with abnormal atrial tissues as identified by voltage mapping or fractionated atrial electrograms (AEGs). The latter are of particular interest (Nademanee et al., 2004): during persAF, fractionated activity has been linked to: i) random activations from meandering wavelets that propagate through the atria; ii) underlying anisotropic conduction in the atrial remodeled tissue; and iii) the occurrence of wave breaks or wave collisions in the atrial tissue (Almeida et al., 2016).

Despite intense effort, the above highlights our lack of understanding of the complex AF pathophysiology and the need of novel biomarkers that better explain patient-specific atrial substrate responsible for AF perpetuation. Recent works have shown that the underlying atrial activations during persAF are spatiotemporally unstable (Almeida et al., 2018a; Haissaguerre et al., 2014; Kimata et al., 2018; Salinet et al., 2013, 2017) and this imposes further limitations for current methods for atrial activation mapping. For instance, two of the most frequently used commercial systems for automated atrial substrate classification during electrophysiological studies, the Ensite NavX ${ }^{\mathrm{TM}}$ (St. Jude Medical, St. Paul, Minnesota) and the CARTO (Biosense Webster, Diamond Bar, California) (Figure 1), still consider sequential point-by-point collection of bipolar AEGs (Almeida et al., 2016). Consequently, studies to better define the shortest possible AEG duration - to reduce the time of the clinical procedure - yet able to identify important electrophysiological phenomena are of great importance.

Recurrence analysis has been shown useful to explore the underlying AF dynamics (Almeida et al., 2018b). Additionally, the dynamics of cardiac signals in the presence of arrhythmias have been extensively investigated in the context of recurrence analysis, especially when considering the main advantages of recurrence quantification analysis (RQA) (Acharya et al., 2015; Arce et al., 2016; Marwan et al., 2002, 2007; Tang et al., 2006; Yang, 2011; Zbilut et al., 2002). However, few works - if any - have investigated RQA-based attributes to objectively characterize the temporal behavior of persAF AEGs (Navoret et al., 2013). In the present work, we sought to characterize the temporal behavior of AEGs with different durations as measured by RQA variables in patients with persAF.

\section{Methods}

\section{Study population and electrophysiological study}

The population consisted of 18 patients ( 16 male; mean age $56.1 \pm 9.3$ years; history of AF $67.2 \pm 45.6$ months) referred to Glenfield Hospital (Leicester, UK) for first time catheter ablation of persAF (Tuan et al., 2011). Details of the clinical characteristics of the study subjects are provided in Table 1. All procedures were performed with full informed consent in a retrospective study according with UK ethics guidelines.

All antiarrhythmic drugs, except amiodarone, were discontinued for at least 5 half-lives before the start of the procedure. Details of the mapping procedure have been described previously (Tuan et al., 2011). Briefly, 3D left atrium (LA) geometry was created within $\mathrm{NavX}^{\mathrm{TM}}$ using a deflectable, variable loop circular PV mapping catheter (Inquiry Optima, St. Jude Medical). PVI was performed with a point-by-point wide area circumferential ablation approach (Cool Path Duo irrigated RF catheter, St. Jude Medical), followed by the creation of a single roof line. PVI was defined as the abolition of electrical signals on the circular mapping catheter when positioned within each PV.

No additional ablation targeting fractionated AEGs was performed in this study. AEG collection was performed for further offline analyses. Sequential point-by-point bipolar AEGs were collected also using the Inquiry Optima from 15 pre-determined atrial regions before and after PVI (Tuan et al., 2011). All patients were in AF before and after PVI during signal collection.

Table 1. Clinical characteristics of study population $(\mathrm{N}=18)$.

\begin{tabular}{lc}
\hline Age (years) & $\mathbf{5 6 . 1} \pm \mathbf{9 . 3}$ \\
Male/Female & $16 / 2$ \\
History of AF, months & $67.2 \pm 45.6$ \\
Ejection Fraction (\%) & $48 \pm 1$ \\
Left Atrial Diameter (mm) & $47 \pm 1$ \\
History of coronary artery disease & 4 \\
Medication* (number of patients on) & 11 \\
ACE inhibitor / ARB & 10 \\
Amiodarone & 8 \\
Beta-blockers & 2 \\
Calcium channel blockers & 1 \\
Digoxin & 5 \\
Sotalol & \\
\hline Values are mean \pm SD or $n$. All anti-arrhythmic and rate-controlling \\
drugs were stopped for at least five half-lives before the procedure, with \\
the exception of amiodarone; *ACE = angiotensin-converting-enzyme; \\
AF = atrial fibrillation; ARB = angiotensin receptor blockers.
\end{tabular}




\section{Signal analysis}

A total of 797 AEGs was recorded from the LA, 455 before and 342 after PVI ( 8 seconds duration; $1200 \mathrm{~Hz}$ sampling frequency; 30-300 Hz band-pass filter built in the NavX system; Matlab's iircomb $50 \mathrm{~Hz}$ Notch filter). A stationary wavelet transform (SWT) filter was implemented based on a previously described method to further reduce both baseline oscillations and high frequency noise (Schilling, 2012). A detailed description of the SWT filter applied to AEGs can be found elsewhere (Almeida et al., 2018b).

\section{The CARTO algorithm (CARTO 3 System, 2008-2014, Version 4.3)}

AEG classification (normal vs. fractionated) was performed following the CARTO criteria. A detailed description of the CARTO system is provided elsewhere (Almeida et al., 2016). Briefly, CARTO provides a 3D

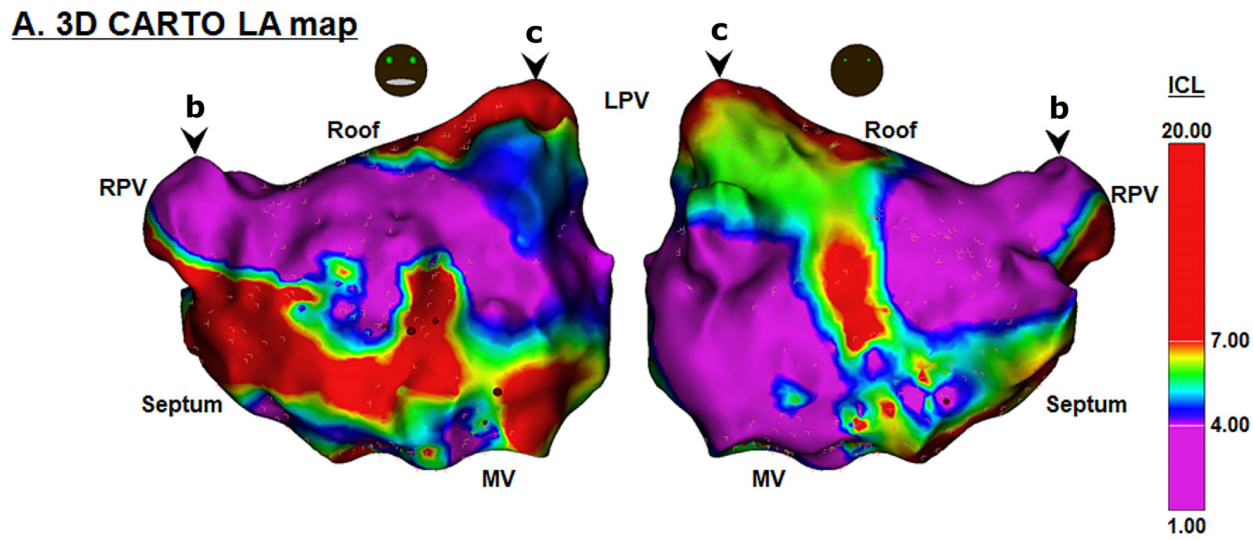

\section{B. Normal AEG}

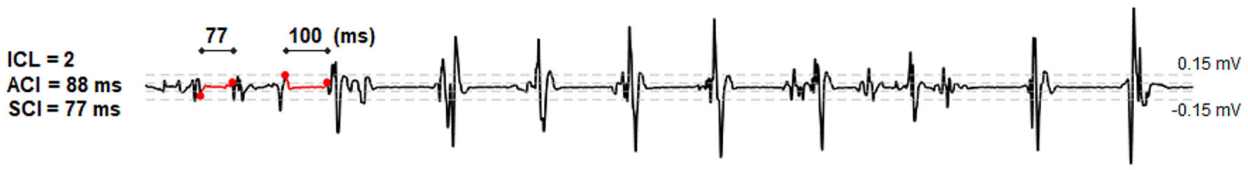

\section{Fractionated AEG}

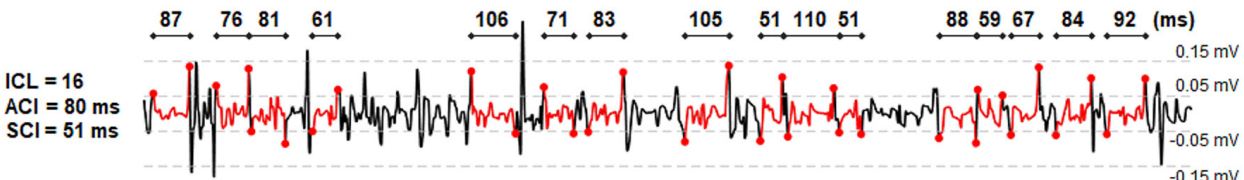

\section{Recurrence plots}
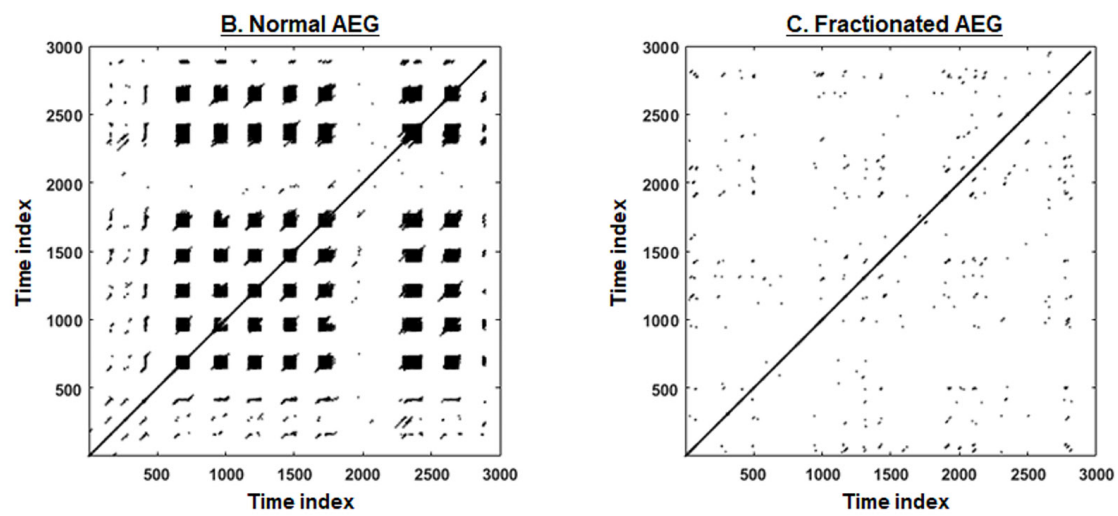

Figure 1. (A) Illustration of automated AEG classification performed by algorithms embedded in commercial systems, with annotated normal (b) and fractionated (c) AEGs. 3D atrial geometry representation for one patient, with the automated AEG classification algorithm performed by the CARTO criteria; (B) Segment of normal AEG with the CARTO annotations; (C) Fractionated AEG with the CARTO annotations; (D) Illustration of the RPs for normal (left-hand side) and fractionated (right-hand side) AEGs. MV = mitral valve; LPV=left pulmonary veins; RPV= right pulmonary veins. 
representation of the LA and online automated AEG classification based on complex intervals between successive peaks and troughs occurring inside a 2.5 seconds window of sequentially recorded bipolar AEGs (Figures 1B and 1C). The number of identified complex intervals is referred to as the interval confidence level (ICL), and characterizes the repetitiveness of the fractionated complexes, which is then converted to a color-coded map that guides ablation. CARTO software also finds, as complementary attributes, the average of the identified interval, referred to as the average complex interval (ACI), and the shortest identified interval, referred to as the shortest complex interval (SCI). A duration of 8 seconds was used for AEG classification following a recent recommendation (Almeida et al., 2018a). AEGs were considered fractionated for $\mathrm{ICL} \geq 4, \mathrm{ACI} \leq 82 \mathrm{~ms}$ and $\mathrm{SCI} \leq 58 \mathrm{~ms}$ (Almeida et al., 2016).

\section{Recurrence quantification analysis}

A Recurrence Plot (RP) consists of a two-'dimensional graphical technique used for the study of the topological structure of multidimensional dynamic systems (Marwan et al., 2007). It aims to evaluate the reappearance of states in a multidimensional vector based on the construction of a binary distance matrix, associating the value " 1 " whenever one point in the multidimensional vector is close to another sample by a distance less than $\varepsilon$, and "0", otherwise (Marwan et al., 2007). This recurrence matrix can be represented graphically by associating a black pixel to the value "1" (Figure 1D). This binary signal "fingerprint" exhibited in the RP is related to its dynamics allowing access to stationarity, regularity and predictability, being useful to characterize phase transitions and the temporal evolution in general, even considering a small amount of data samples, since information concerning the distance organization between all pairs of points is taken into account in time and phase space (Soriano et al., 2009, 2011).

Complex patterns in RPs can be reduced to primary diagonal, vertical and horizontal dot patterns aligned on a grid (Webber and Zbilut, 2007). It is the mixing and matching of these primary structures that gives rise to all derivative graphical complexities and allows for the quantification of the recurrence organization. Therefore, RQA was established by introducing statistical variables considering the distribution of diagonal and vertical lines of different sizes in the RP (Webber and Zbilut, 1994). Since usually just a single observation (the AEG) is available for a time window, the phase space can be reconstructed using the Takens' theorem (Marwan et al., 2007), aiming to reveal a possibly hidden low dimensional geometric trajectory underlying the observation. In this case, the auxiliary axes are estimated considering delayed samples of the unidimensional observation $\mathbf{x}(k)$, such as:

$$
\mathrm{x}(k)=\left[x(k), x(k-\tau), \ldots, x\left(k-\left(d_{e}-1\right) \tau\right)\right]
$$

in which $d_{e}$ is the embedding dimension - number of coordinates used for the $\mathrm{x}(k)$ representation - and $\tau$ represents the time-delay embedding among samples. These parameters were estimated through the false nearest neighbor test and the first local minimum of the self-mutual information, respectively, as classically performed in nonlinear analysis devoted to RP and RQA (Marwan et al., 2007; Marwan, 2011).

The recurrence matrix $\left(\mathrm{R}_{i, j}\right)$ was defined based on the distance between the respective reconstructed states $\boldsymbol{x}_{\boldsymbol{i}}$ and $\boldsymbol{x}_{\boldsymbol{j}}$ and an arbitrary threshold $\varepsilon$ for defining a binary proximity relation, which can be expressed as:

$$
R_{i, j}(\varepsilon)=\theta\left\{\varepsilon-\left\|\boldsymbol{x}_{i}-\boldsymbol{x}_{j}\right\|\right\}
$$

being $\theta\{\{\}$ the Heaviside function.

The binary pattern observed in a RP is intrinsically related to the generative dynamics of the observation: the horizontal structures are associated with the laminarity (or turbulence) of the signal; the diagonal structures reflect the co-evolution of states and indicate possible deterministic dynamics. For a RP obtained from a time series of $N$ samples, with frequency distribution $\mathrm{P}(l)$ of diagonal line's length, frequency distribution $\mathrm{P}(v)$ of vertical line's length, probability $\mathrm{p}(l)$ of finding a diagonal of length $l$ (i.e. $\mathrm{P}(l)$ normalized by the total amount of diagonals found in the RP), the RQA is associated with representative statistical measures of the matrix $\mathrm{R}_{i, j}$ (Marwan et al., 2007), being used here:

- The recurrence rate (RR), which represents the density of points in a RP:

$$
R R=\frac{1}{N^{2}} \sum_{i, j=1}^{N} R_{i, j}
$$

- The ratio between recurrence points that form diagonal structures (with length $l \geq l_{\text {min }}$ ), referred to as determinism (DET):

$$
D E T=\frac{\sum_{l=l_{\min } \mathrm{P}(l)}^{N} \sum_{l=1}^{N} \mathrm{P}(l)}{\mathrm{P}_{\mathrm{m}}(l)}
$$

- The Shannon entropy of diagonal lines in a RP (ENTR), which reflects the RP's complexity regarding the diagonal lines:

$$
E N T R=-\sum_{l=l_{\min }}^{N} p(l) \ln p(l)
$$

- The ratio between recurrence points that form vertical structures (with length $v \geq v_{\text {min }}$ ), referred to as laminarity (LAM):

$$
L A M=\frac{\sum_{v=v_{\text {min }}}^{N} v \mathrm{P}(v)}{\sum_{v=1}^{N} v \mathrm{P}(v)}
$$


The theoretical methodology and specificities of RQA for the investigation of AEGs during persAF have been provided elsewhere (Almeida et al., 2018b). Briefly, an adaptive value for $\varepsilon$ based on $2 \%$ of the maximum phase space diameter of each AEG was chosen since it offers a good compromise among the resulting recurrence rate (RR) - as close to $1 \%$ as possible as suggested by previous work (Marwan et al., 2007) - but also with a good compromise between the AEG discrimination and the portion of the maximum phase space diameter, accordingly (Mindlin and Gilmore, 1992):

$$
\varepsilon=2 \cdot 10^{-2} \times \max \left\{\left\|\boldsymbol{x}_{i}-\boldsymbol{x}_{j}\right\|\right\}
$$

Determinism (DET) and laminarity (LAM) were calculated considering minimum line lengths of 6 and 7 , respectively, to avoid undesirable saturation behavior and for improved AEG discrimination.

\section{RQA-based attributes with different AEG durations and statistical analysis}

All continuous non-normally distributed variables are expressed as median \pm interquartile interval. Non-parametric unpaired data were analyzed using the Friedman test with Dunn's correction.

The AEGs exported from NavX with 8 seconds were segmented in smaller durations, accordingly: $0.5 ; 0.6 ; 0.7$; $0.8 ; 0.9 ; 1 ; 1.5 ; 2 ; 2.5 ; 3 ; 3.5 ; 4 ; 4.5 ; 5 ; 6$; and 7 seconds. This resulted in different numbers of non-overlapping segments for each duration - i.e., 16 segments for 0.5 seconds; 13 for 0.6 seconds; 11 for 0.7 seconds; 10 for 0.8 seconds; 8 for 0.9 and 1 seconds; 5 for 1.5 seconds; 4 for 2 seconds; 3 for 2.5 seconds; 2 for $3,3.5$ and 4 seconds; and 1 segment for $4.5,5,6$, 7 and 8 seconds.

The RQA-based variables were calculated considering each AEG duration. All durations were compared with 8 seconds - considered in the present work as the (best possible) reference. Spearman's correlation ( $\rho$ ) was calculated to quantify the correlation between AEG classifications measured with the different durations versus 8 seconds.

The dichotomous classification performed by CARTO (normal or fractionated) for AEGs with 8 seconds was used as a reference to create the Receiver operating characteristic (ROC) curves considering each RQA variable as discriminators for each AEG duration. The optimum sensitivity and specificity for each ROC curve (i.e., each RQA variable for each duration from 0.5 to 8 seconds) was defined as the point on the curve with the shortest distance to the top left corner of the graph (Youden's index). Validation of the optimum point of operation for AEG classification was performed with leave-one-out cross-validation (LOOCV).
The optimum points of operations found in each ROC curve were used to perform new AEG classifications. For this, AEGs with 8 seconds were divided in segments with duration from 0.5 to 4 seconds - e.g., 16 segments of 0.5 seconds and 2 segments of 4 seconds, respectively - as described above. The RQA variables were calculated for each segment and used to categorize the AEG (normal or fractionated) according to the optimum point of operation found in the ROC curve for that particular AEG duration. Finally, AEGs in which all segments were classified as normal were defined as consistently normal; AEGs in which all segments were classified as fractionated were defined as consistently fractionated; AEGs in which the classification varied within segments (normal to fractionated and/or vice-versa) were defined as temporally unstable.

P-values of less than 0.05 were considered statistically significant.

\section{Results}

\section{Effect of AEG duration on the RQA variables}

Figure 2 illustrates the effect of AEG durations on the RQA variables (DET, RR, LAM and ENTR, respectively). The variables increase with the increase in the duration of AEGs. There was no statistical difference in DET, LAM and ENTR calculated with 6 and 7 seconds when compared to 8 seconds, whereas the RR showed no significant difference between 7 and 8 seconds. Figure 3 illustrates the correlation between the RQA variables calculated with 8 seconds versus all other durations. Although there were significant differences with durations of less than 6 seconds - as shown in Figure 2 - a high correlation was observed among AEGs with 3 seconds (and longer) and 8 seconds ( $\rho \geq 80 \%$ ).

\section{Effect of AEG duration on AEG classification with $R Q A$ variables}

The ROC optimum operating points found for each RQA variable and AEG durations are shown in the Table 1. Figure 4A illustrates the area under the ROC curves (AUROC) created using the CARTO criteria for AEG classification with 8 seconds as the reference, and the RQA variables as discriminators for each AEG duration, and Figure 4B shows the LOOCV for each case. In this case, the hit rate refers to the discrepancy level between CARTO- and RQA-based classification. While the AUROC gradually increases for all RQA variables with increase of AEG duration, AEGs with 4 seconds presented the highest hit rate in AEG classification considering the CARTO criteria as the reference (Figure 4B). 
A.

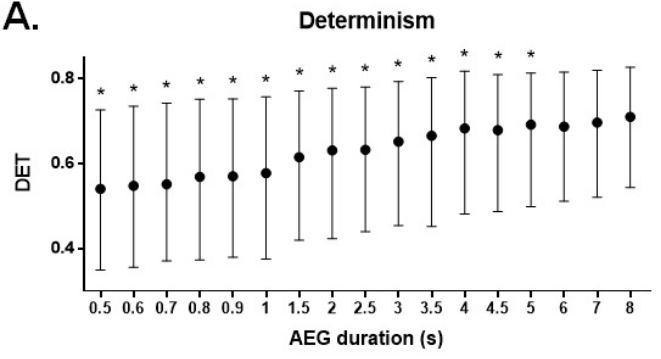

B.

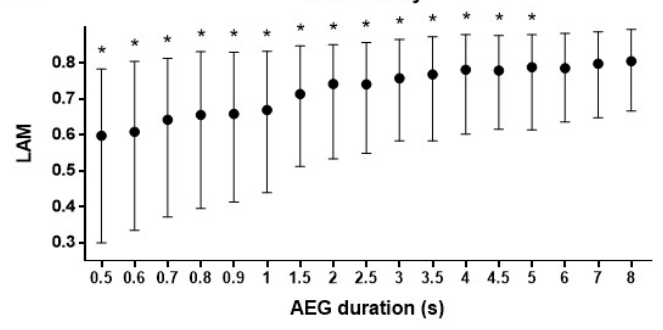

C.

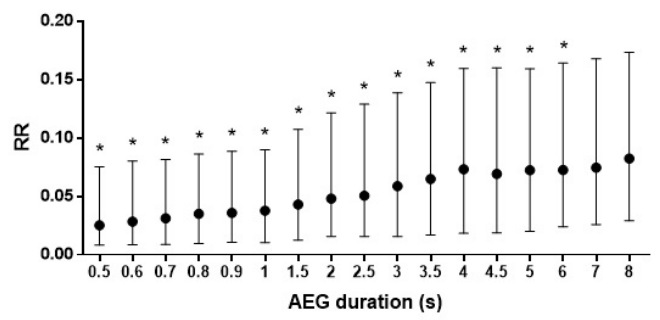

D. Entropy of diagonal lines

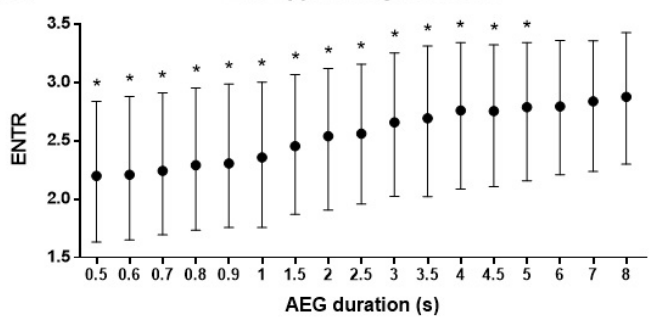

Figure 2. (A) DET; (B) LAM; (C) RR; (D) ENTR calculated with each AEG duration $(0.5 ; 0.6 ; 0.7 ; 0.8 ; 0.9 ; 1 ; 1.5 ; 2 ; 2.5 ; 3 ; 3.5 ; 4 ; 4.5 ; 5 ; 6 ; 7$; 8 seconds). ${ }^{*} \leq \mathrm{P} 0.05$ vs. 8 seconds. $\mathrm{DET}=$ Determinism; LAM $=$ Laminarity; $\mathrm{RR}=$ recurrence rate; ENTR $=$ entropy of the diagonal lines.
Figures 5 to 7 illustrate typical normal, fractionated and unstable (i.e., changing from normal to fractionated or vice-versa) AEGs, respectively, found in the present cohort, with the time evolution of the RQA variables calculated for 0.5 seconds and their respective ROC optimum points of operation.

Figure 8 shows, for each RQA variable, the portion of AEGs classified as consistently normal, consistently fractionated and temporally unstable within the segments defined by each AEG duration. AEGs divided in segments with short duration (shorter than 1.5 seconds) resulted in a high number of temporally unstable AEGs, suggesting that such short segments might be highlighting fast local oscillations. However, the number of temporally unstable AEGs seems to have converged in AEG segments with 3 seconds or longer.

\section{Discussion}

In this work, we investigated the temporal behavior of bipolar AEGs collected during persAF using RQA additional to the automated AEG classification performed by CARTO. Optimum points of operation were found for the RQA variables to objectively perform AEG classification, and these variables were effective in identifying underlying changes in atrial activations. The duration of the AEGs had profound effect on the RQA variables, in which shorter segments might be more sensitive to identify fast and local changes, while longer segments might provide a more general perspective of the dynamics of the underlying atrial tissue. The results support recent findings that $\mathrm{AF}$ is a dynamic arrhythmia (Almeida et al., 2018a; Haissaguerre et al., 2014; Kimata et al., 2018; Navoret et al., 2013; Salinet et al., 2013, 2017), and RQA variables can be used as a complementary tool for the characterization of atrial substrate during persAF targeted ablation (Almeida et al., 2018b).

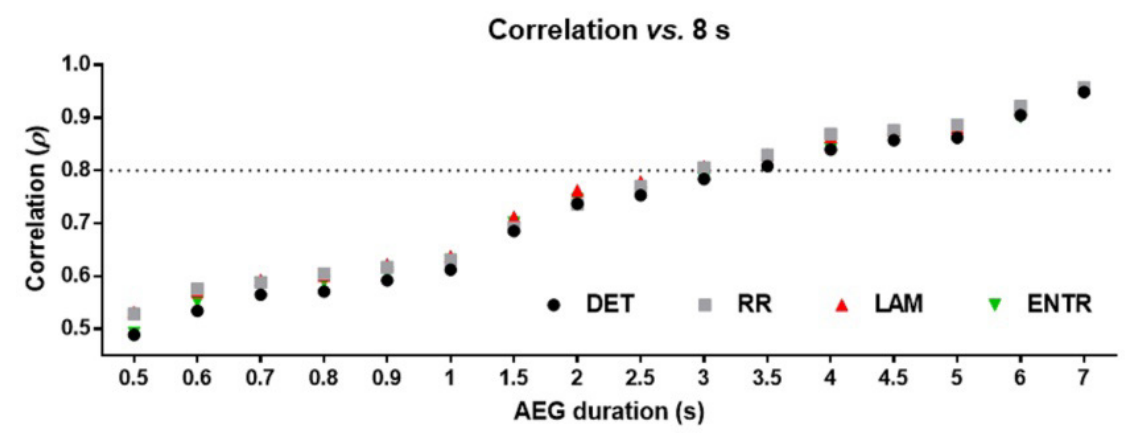

Figure 3. Spearman's correlation of each AEG durations versus 8 seconds for each RQA variable. DET = Determinism; RR = recurrence rate; LAM $=$ Laminarity; ENTR = entropy of the diagonal lines. 
A.

Area under the ROC curve

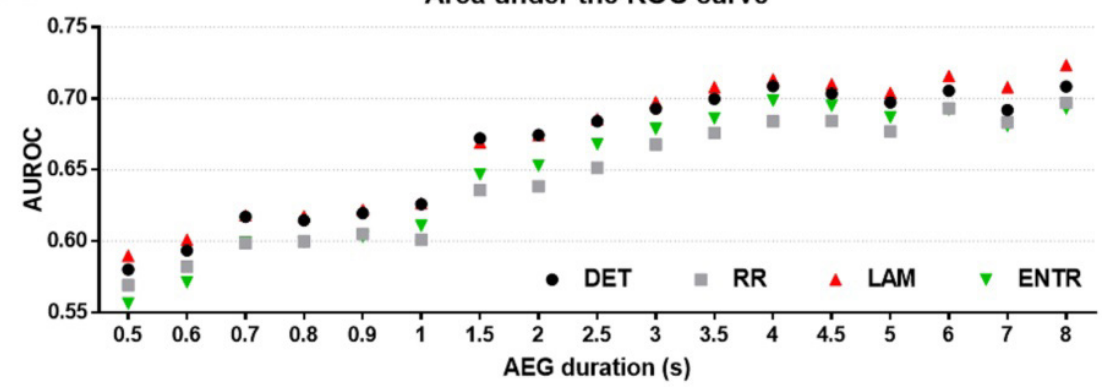

B.

Leave-one-out cross-validation

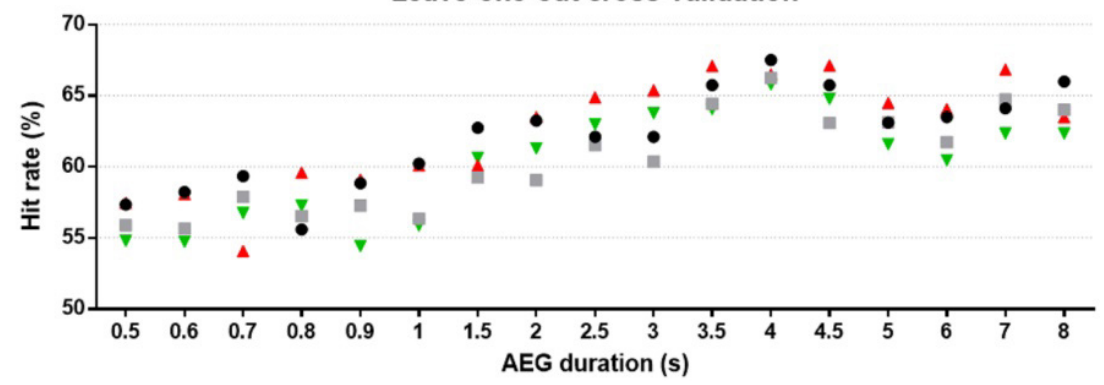

Figure 4. (A) AUROC for the RQA variables and each AEG duration considering the CARTO criteria as the reference for AEG classification; (B) The hit rate for the LOOCV for the RQA variables and each AEG duration. DET = Determinism; RR = recurrence rate; LAM = Laminarity; $\mathrm{ENTR}=$ entropy of the diagonal lines.

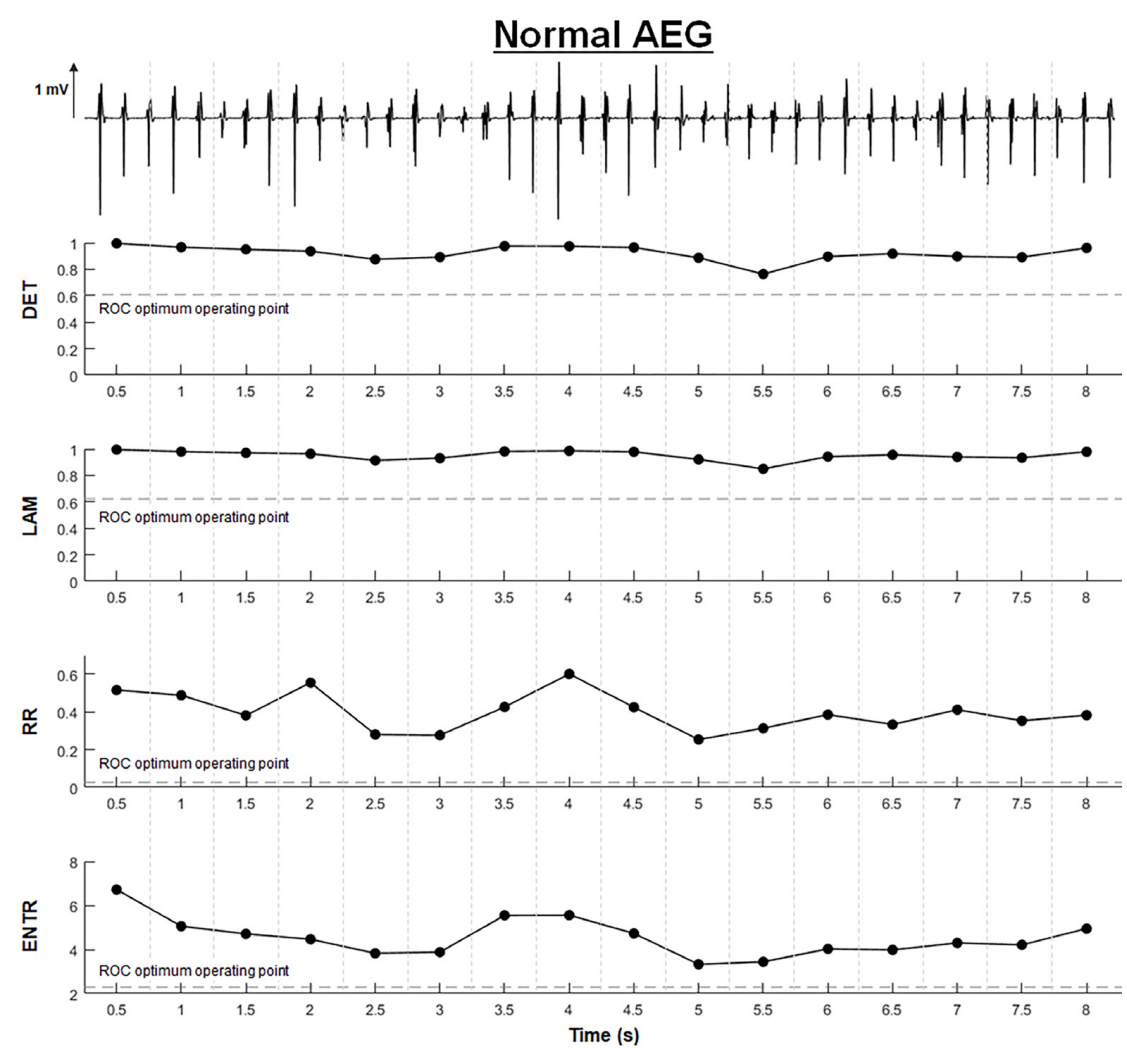

Figure 5. Example of an AEG classified as consistently normal by all RQA variables and the evolution in time of each RQA variable (DET, LAM, RR and ENTR) and their respective ROC optimum points of operation. All RQA variables remained above their respective ROC optimum points of operation. $\mathrm{DET}=$ Determinism; $\mathrm{RR}=$ recurrence rate; $\mathrm{LAM}=$ Laminarity; $\mathrm{ENTR}=$ entropy of the diagonal lines. 


\section{Fractionated AEG}

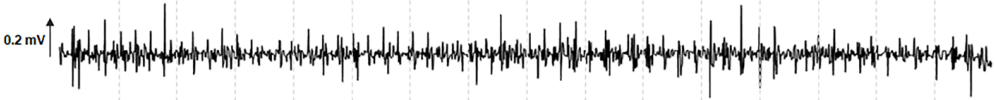
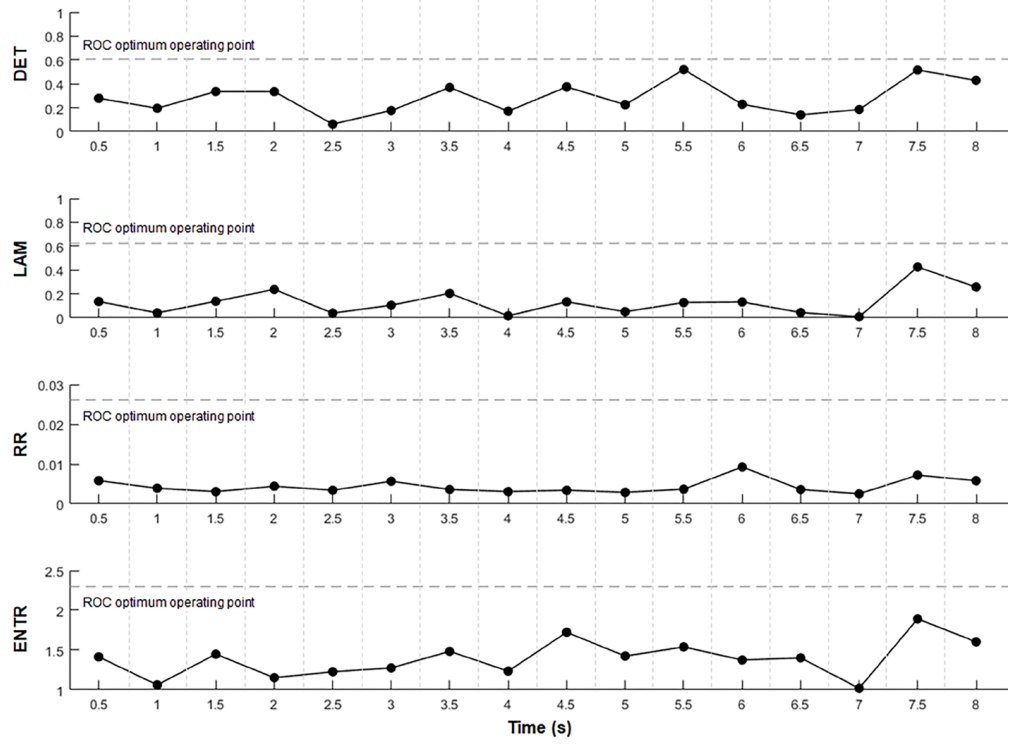

Figure 6. Example of an AEG classified as consistently fractionated by all RQA variables and the evolution in time of each RQA variable (DET, LAM, RR and ENTR) and their respective ROC optimum points of operation. All RQA variables remained below their respective ROC optimum points of operation. $\mathrm{DET}=$ Determinism; LAM $=$ Laminarity; RR $=$ recurrence rate; ENTR = entropy of the diagonal lines.
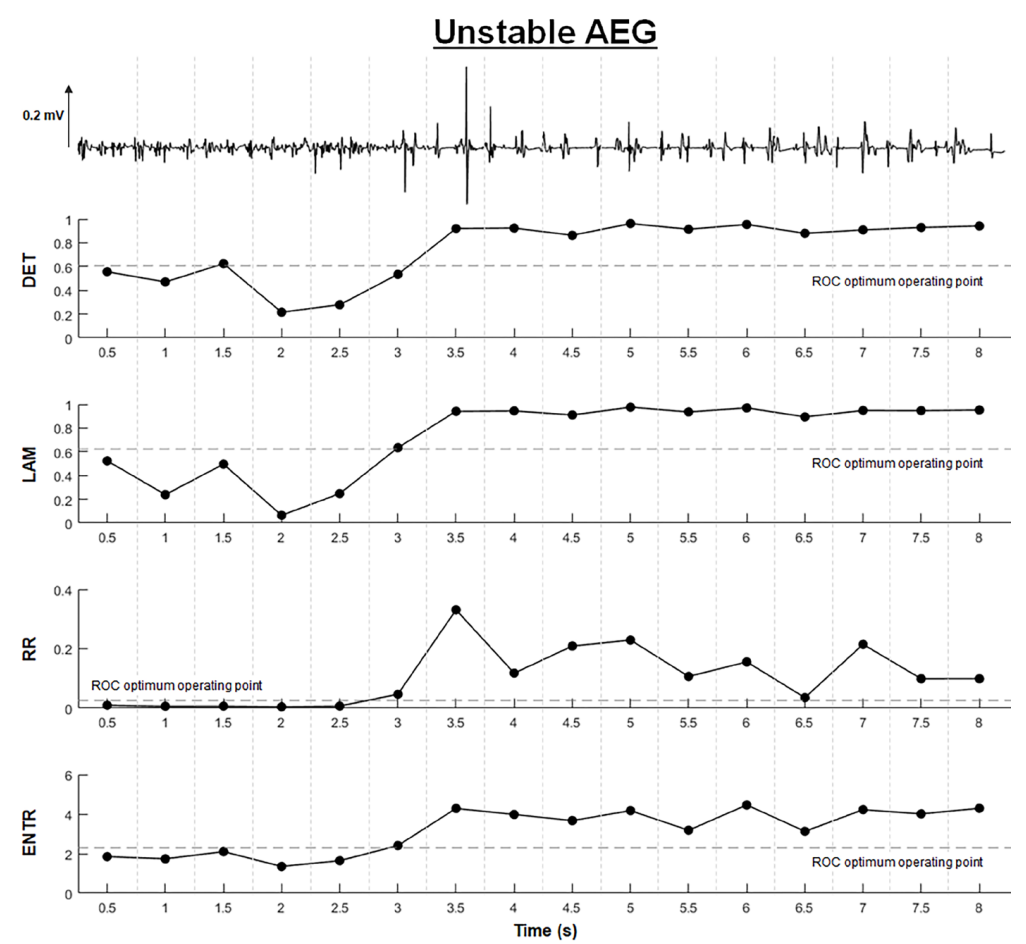

Figure 7. Example of an AEG classified as temporally unstable by all RQA variables and the evolution in time of each RQA variable (DET, LAM, RR and ENTR) and their respective ROC optimum points of operation. All RQA variables oscillated within their respective ROC optimum points of operation. $\mathrm{DET}=$ Determinism; LAM = Laminarity; RR = recurrence rate; ENTR = entropy of the diagonal lines. 
A.

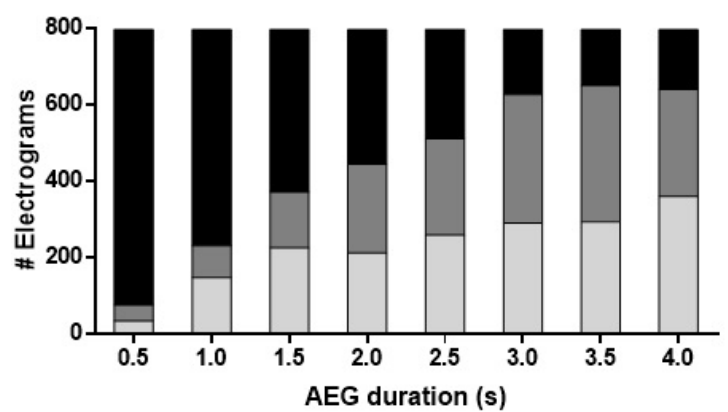

B.

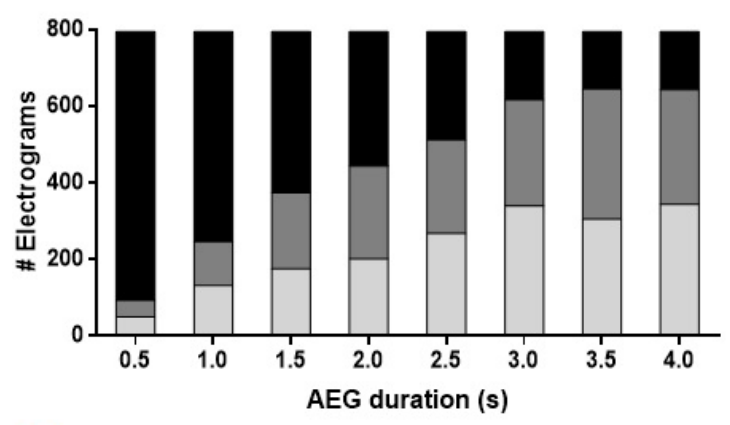

C.

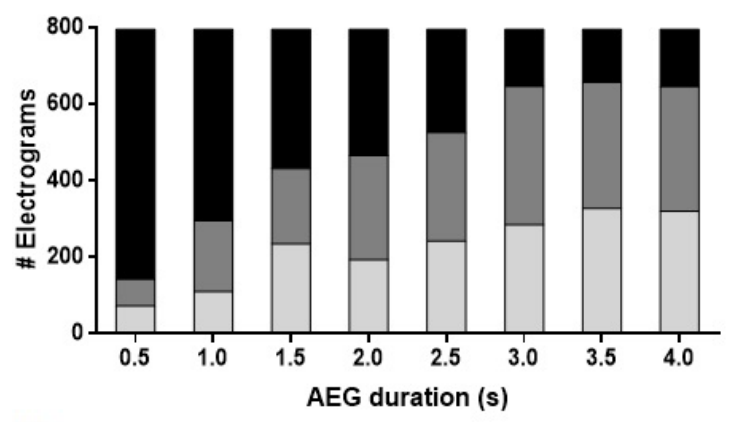

D.

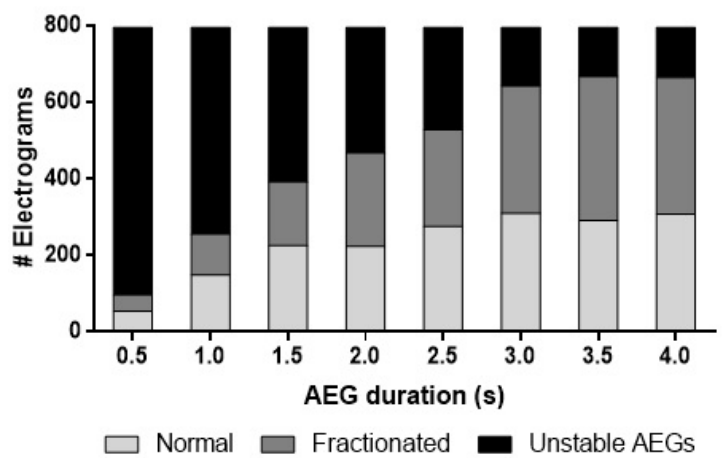

Figure 8. The portion of AEGs classified as consistently normal, consistently fractionated and temporally unstable within each AEG duration for each RQA variable: (A) Determinism; (B) Recurrence rate; (C) Laminarity; (D) Entropy of the diagonal lines.

\section{Mechanisms for AF perpetuation and maintenance}

Despite much effort to understand atrial substrate properties during persAF, the dynamic nature of $\mathrm{AF}$ continues to pose challenge for electrophysiologists in search of critical sites for ablation (Almeida et al., 2018a; Haissaguerre et al., 2014; Redfearn et al., 2009; Roux et al., 2008; Salinet et al., 2013, 2017; Stiles et al., 2008; Tsai et al., 2012; Verma et al., 2008). For instance, although early works have suggested that atrial activations during persAF demonstrate a high degree of spatial and temporal stability (Redfearn et al., 2009; Roux et al., 2008; Verma et al., 2008), more recent works have highlighted the unstable behavior of underlying atrial activations during persAF - yet with preferential sites for recurrence (Almeida et al., 2018a; Haissaguerre et al., 2014; Salinet et al., 2013, 2017). Additionally, recently published works have shown fractionated activity from the pivot points of reentry circuits (Frontera et al., 2018), and a high correlation between the recurrence of reentry circuits and atrial regions with high fibrosis density (Cochet et al., 2018). These results reinforce the initial perception that fractionation in AEGs could represent areas of remodeled atrial substrate with high density of fibrosis with participation of reentry circuits (Nademanee et al., 2004), from which multiple wavelets might emanate and meander in the atrial tissue, with direct participation in the perpetuation of the arrhythmia. Considering that remodeled tissue is anchored in the atria, such regions would present consistent fractionated activity, and hence should be considered as the premier targets for ablation. Similarly, atrial regions with unstable behavior -i.e., changing from normal to fractionated or vice-versa-should not be preferred as targets for ablation, as the fractionation might be a result of passive turbulent activations and, therefore, not a true representation of atrial substrate (Jadidi et al., 2012; Rostock et al., 2006; Roux et al., 2009; Tuan et al., 2011).

Our results support these findings, in which RQA variables identified AEGs with i) consistent normal activations; ii) consistent fractionated activations and; iii) unstable behavior. More specifically, atrial regions subjected to passive turbulent activations - facilitated by the presence of multiple meandering wavelets, wave break and wave collision - would be more prone to the occurrence of temporally unstable AEGs. Previous work has shown that far-field components can induce potential distortions that explain the instability of the underlying activations (Rodrigo et al., 2014). Such activations would induce the occurrence of seemingly fractionated activity in the collected AEG, in this case unrelated to the integrity and characteristics of the underlying atrial tissue. On the one hand, healthy regions could be affected by passive wave collision from remote AF drivers and, 
consequently, demonstrate temporally unstable fractionated activity. The ablation of such regions might create areas of slow or anisotropic conduction, thereby creating pro-arrhythmogenic areas which would perpetuate the arrhythmia instead of organizing or terminating it. On the other hand, atrial regions with direct participation in $\mathrm{AF}$ perpetuation - e.g., regions with fibrotic tissue - would demonstrate consistent fractionated activity associated with the underlying remodeled tissue, which is anchored in the atria (Zaman and Narayan, 2015).

\section{Methods and biomarkers for AF mapping}

Contact and noncontact methods have been introduced for global endocardial mapping to provide simultaneous recordings of intracardiac activity and, consequently, a comprehensive perspective of the cardiac chambers' anatomy and electrophysiology (Schilling et al., 1998; Schmitt et al., 1999). Although these methods facilitate the investigation of the spatiotemporal behavior of cardiac activations, they face limitations such as poor quality of the reconstructed AEG in the case of noncontact mapping (Schilling et al., 1998), and poor contact quality between the poles of basket catheters and the cardiac wall in the case of contact mapping (Buch et al., 2016). Additionally, focal Impulse and Rotor Modulation (FIRM)-guided ablation, that has been received with great enthusiasm as a therapy for persAF from simultaneous mapping (Narayan et al., 2012), has been questioned by more recent research (Buch et al., 2016). Also, we have shown that, although rotors seem to meander in the atria, they have preferential sites for recurrence, which could represent regions of remodeled substrate (Salinet et al., 2017).

Contact point-by-point sequential AEG mapping is still performed by clinical groups using commercial systems during electrophysiological studies (Almeida et al., 2016; Gepstein et al., 1997; Stevenson and Soejima, 2005). Therefore, many works investigated biomarkers to better characterize the underlying AF dynamics from AEGs collected sequentially. For instance, previous works have shown that AEGs with 4 seconds or longer should be preferred during electrophysiological studies using biomarkers from commercial systems (Almeida et al., 2018a; Stiles et al., 2008; Tsai et al., 2012). A recent work has implemented a time-frequency analysis with Wavelet Transform to identify atrial regions with a stable dominant frequency, suggesting that those sites represent AF drivers and hence should be preferred for catheter ablation (Kimata et al., 2018). Finally, mapping of wave similarity during AF has been introduced as a powerful alternative biomarker in the investigation of spatiotemporal distribution of fibrillatory wave complexity (Ravelli et al., 2005).
Recurrence analysis has been previously used for the investigation of AF dynamics. We have recently shown that RQA variables are sensitive to important electrophysiologic characteristics of the atrial tissue (Almeida et al., 2018b). More specifically, we demonstrated that the RQA variables were significantly affected by PVI, and that the variables were effective in discriminating normal vs. fractionated AEGs. Therefore, RQA variables could be potentially used as biological markers to guide the clinical procedure. Navoret and colleagues have used RQA-based variables in the classification of AEGs and investigated the temporal dynamics of AEGs during AF without, however, suggesting thresholds for AEG classification (Navoret et al., 2013). Another work has used RPs to show that atrial regions with stable rotors exhibited stable, periodic dynamics, while regions of wavelet breakup have shown a chaotic behavior largely devoid of repetitive activation patterns (Hummel et al., 2017). This work is the first to objectively investigate the temporal behavior of persAF AEGs using RQA variables and to provide thresholds for AEG classification with different AEG durations. Our results suggest that RQA variables can be calculated considering AEGs with 3 seconds or longer during electrophysiological studies, i.e., shorter duration than current recommendations (Almeida et al., 2018a).

The current study was limited to retrospective data. Further understanding of the underlying cardio-electrophysiological mechanisms behind persAF would be helpful for the validation of the suggested method, such as in (i) computational intracardiac models that simulate both atrial electrical activity and ablation procedures during AF (Krueger et al., 2013); and (ii) prospective studies using the suggested method in the identification of ablation targets during substrate mapping. Additionally, we acknowledge that the simplistic and non-physiologic rationale behind the counting of the number of fractionated deflections as performed by the CARTO algorithm might also impose some limitations. This, however, deserves a dedicated investigation that is out of the scope of the present work.

Different mechanisms are likely to participate in persAF perpetuation linked to remodeled substrate, such as the rapidly discharging automatic foci (Haissaguerre et al., 1998); the multiple wavelets hypothesis (Konings et al., 1994); the single reentrant circuit with fibrillatory conduction (Jalife et al., 2002); the conduction dissociation between epicardial and endocardial layers (Groot et al., 2016); and functional reentry resulting from rotors (Narayan et al., 2012). These mechanisms are likely to co-exist either simultaneously or intermittently, resulting in an intricate structure of atrial activations. Accordingly, recent works have highlighted the unstable - yet recurrent - behavior of underlying atrial activations during persAF (Almeida et al., 2018a; Haissaguerre et al., 2014; Salinet et al., 2013, 
2017). Rotors have been shown to be spatiotemporally unstable, appearing and disappearing in different atrial regions (Haissaguerre et al., 2014; Salinet et al., 2017). The same works, however, have shown that, although reentry circuits meander in the atria, they have preferential sites for recurrence.

We have recently argued that fractionated activity could be related to areas of high density of fibrosis that would induce the formation of reentry circuits, from which multiple wavelets might emanate and meander in the atrial tissue, with direct participation in the perpetuation of the arrhythmia (Almeida et al., 2018b). Additionally, previous study has shown that the RPs from areas of stable spiral wave reentry exhibited stable, periodic dynamics, while regions of wavelet breakup have shown a chaotic behavior largely devoid of repetitive activation patterns (Hummel et al., 2017). Therefore, the identification of a better segment duration for persAF classification using RQA could be related to the intrinsic characteristics of RQA to correlate with the periodic dynamics found within areas of reentry circuits, even if these reentries present an unstable yet recurrent - spatiotemporal behavior. Clearly, it is not possible to have this confirmed with the method presented here due to the fact that we do not know the 'ground truth' for AF perpetuation in this cohort. Still, further investigations with either simultaneous AEG collection or simulated AF episodes could help to better understand the underlying AF dynamics.

In conclusion, we characterized the temporal behavior of the underlying dynamics of atrial tissue activations from AEGs collected during persAF using RPs and RQA-based variables. We have found optimum points of operation for the RQA variables to objectively perform AEG classification, and we have shown that the RQA variables were effective in identifying underlying changes in atrial activations. The variables identified AEGs with consistent normal activations, consistent fractionation and AEGs with unstable behavior. The duration of the AEGs had profound effect on the RQA variables, but RQA variables allowed the characterization of AEGs collected during persAF with a shorter duration ( 3 seconds) than current recommendations. RQA variables could be used by electrophysiologists as a complementary tool during atrial substrate mapping to guide persAF ablation.

\section{Acknowledgements}

The authors thank Prof. Takashi Yoneyama and Prof. Eduardo T. Costa for their valuable suggestions. The work reported in this paper was supported by the NIHR Leicester Biomedical Research Centre. DCS received Conselho Nacional de Desenvolvimento Científico e Tecnológico financial support (CNPq, 449467/2014-7 and 305616/2016-1). JS received grants from CNPq (200598/2009-0) and Fundação de Amparo à Pesquisa do Estado de São Paulo (FAPESP, 2015/12799-9). TPA received research grants from $\mathrm{CNPq}(200251 / 2012-0)$, Coordenação de Aperfeiçoamento de Pessoal de Nível Superior (CAPES, Brazil) and FAPESP (2017/00319-8).

\section{References}

Acharya UR, Fujita H, Sudarshan VK, Ghista DN, Lim WJE, Koh JE. Automated prediction of sudden cardiac death risk using kolmogorov complexity and recurrence quantification analysis features extracted from hrv signals. In: IEEE International Conference on Systems, Man, and Cybernetics; 2015 Oct 9-12; Hong Kong. USA: IEEE; 2015. p. 1110-5. http://dx.doi. org/10.1109/SMC.2015.199.

Almeida TP, Chu GS, Salinet JL, Vanheusden FJ, Li X, Tuan JH, Stafford PJ, Ng GA, Schlindwein FS. Minimizing discordances in automated classification of fractionated electrograms in human persistent atrial fibrillation. Med Biol Eng Comput. 2016; 54(11):1695-706. http://dx.doi.org/10.1007/s11517016-1456-2. PMid:26914407.

Almeida TP, Chu GS, Bell MJ, Li X, Salinet JL, Dastagir N, Tuan JH, Stafford PJ, André Ng G, Schlindwein FS. The temporal behavior and consistency of bipolar atrial electrograms in human persistent atrial fibrillation. Med Biol Eng Comput. 2018a; 56(1):71-83. http://dx.doi.org/10.1007/s11517-0171667-1. PMid:28674778.

Almeida TP, Schlindwein FS, Salinet J, Li X, Chu GS, Tuan JH, Stafford PJ, André Ng G, Soriano DC. Characterization of human persistent atrial fibrillation electrograms using recurrence quantification analysis. Chaos. 2018b; 28(8):085710-1-12. http://dx.doi.org/10.1063/1.5024248. PMid:30180613.

Arce H, Fuentes A, González GH. Recurrence analysis of cardiac restitution in human ventricle. In: Webber JC, Ioana C, Marwan N, editors. Recurrence plots and their quantifications: expanding horizons. Cham: Springer; 2016. (Springer Proceedings In Physics). http://dx.doi.org/10.1007/978-3-319-29922-8_9.

Bakker JMT, Wittkampf FHM. The pathophysiologic basis of fractionated and complex electrograms and the impact of recording techniques on their detection and interpretation. Circ Arrhythm Electrophysiol. 2010; 3(2):204-13. http://dx.doi. org/10.1161/CIRCEP.109.904763. PMid:20407105.

Buch E, Share M, Tung R, Benharash P, Sharma P, Koneru J, Mandapati R, Ellenbogen KA, Shivkumar K. Long-term clinical outcomes of focal impulse and rotor modulation for treatment of atrial fibrillation: a multicenter experience. Heart Rhythm. 2016; 13(3):636-41. http://dx.doi.org/10.1016/j. hrthm.2015.10.031. PMid:26498260.

Calkins H, Hindricks G, Cappato R, Kim YH, Saad EB, Aguinaga L, Akar JG, Badhwar V, Brugada J, Camm J, Chen PS, Chen SA, Chung MK, Nielsen JC, Curtis AB, Davies DW, Day JD, d'Avila A, de Groot NMSN, Di Biase L, Duytschaever M, Edgerton JR, Ellenbogen KA, Ellinor PT, Ernst S, Fenelon G, Gerstenfeld EP, Haines DE, Haissaguerre M, Helm RH, Hylek E, Jackman WM, Jalife J, Kalman JM, Kautzner J, Kottkamp H, Kuck KH, Kumagai K, Lee R, Lewalter T, Lindsay BD, Macle L, Mansour M, Marchlinski FE, Michaud GF, Nakagawa H, Natale A, Nattel S, Okumura K, Packer D, Pokushalov E, Reynolds MR, Sanders P, Scanavacca M, Schilling R, Tondo 
C, Tsao HM, Verma A, Wilber DJ, Yamane T. 2017 HRS/ EHRA/ECAS/APHRS/SOLAECE expert consensus statement on catheter and surgical ablation of atrial fibrillation. Heart Rhythm. 2017; 14(10):e275-444. http://dx.doi.org/10.1016/j. hrthm.2017.05.012. PMid:28506916.

Clarnette JA, Brooks AG, Mahajan R, Elliott AD, Twomey DJ, Pathak RK, Kumar S, Munawar DA, Young GD, Kalman JM, Lau DH, Sanders P. Outcomes of persistent and long-standing persistent atrial fibrillation ablation: a systematic review and meta-analysis. Europace. 2018; 20(FI_3):f366-76. http://dx.doi. org/10.1093/europace/eux297. PMid̄:29267853.

Cochet H, Dubois R, Yamashita S, Al Jefairi N, Berte B, Sellal J-M, Hooks D, Frontera A, Amraoui S, Zemoura A, Denis A, Derval N, Sacher F, Corneloup O, Latrabe V, ClémentGuinaudeau S, Relan J, Zahid S, Boyle PM, Trayanova NA, Bernus O, Montaudon M, Laurent F, Hocini M, Haïssaguerre M, Jaïs P. Relationship between fibrosis detected on late gadolinium-enhanced $\mathrm{cmr}$ and re-entrant activity assessed with ecgi in human persistent atrial fibrillation. JACC Clin Electrophysiol. 2018; 4(1):17-29. http://dx.doi.org/10.1016/j. jacep.2017.07.019. PMid:29479568.

Frontera A, Takigawa M, Martin R, Thompson N, Cheniti G, Massoullié G, Duchateau J, Wielandts JY, Teijeira E, Kitamura T, Wolf M, Al-Jefairi N, Vlachos K, Yamashita S, Amraoui S, Denis A, Hocini M, Cochet H, Sacher F, Jaïs P, Haïssaguerre M, Derval N. Electrogram signature of specific activation patterns: analysis of atrial tachycardias at high-density endocardial mapping. Heart Rhythm. 2018; 15(1):28-37. http://dx.doi. org/10.1016/j.hrthm.2017.08.001. PMid:28797676.

Gepstein L, Hayam G, Benhaim SA. A novel method for nonfluoroscopic catheter-based electroanatomical mapping of the heart: in vitro and in vivo accuracy results. Circulation. 1997; 95(6):1611-22. http://dx.doi.org/10.1161/01.CIR.95.6.1611. PMid:9118532.

Groot N, van der Does L, Yaksh A, Lanters E, Teuwen C, Knops P, Van de Woestijne P, Bekkers J, Kik C, Bogers A, Allessie M. Direct proof of endo-epicardial asynchrony of the atrial wall during atrial fibrillation in humans. Circ Arrhythm Electrophysiol. 2016; 9(5):e003648. http://dx.doi.org/10.1161/ CIRCEP.115.003648. PMid:27103089.

Haissaguerre M, Hocini M, Denis A, Shah AJ, Komatsu Y, Yamashita S, Daly M, Amraoui S, Zellerhoff S, Picat MQ, Quotb A, Jesel L, Lim H, Ploux S, Bordachar P, Attuel G, Meillet V, Ritter P, Derval N, Sacher F, Bernus O, Cochet H, Jais P, Dubois R. Driver domains in persistent atrial fibrillation. Circulation. 2014; 130(7):530-8. http://dx.doi.org/10.1161/ CIRCULATIONAHA.113.005421. PMid:25028391.

Haissaguerre M, Jais P, Shah DC, Takahashi A, Hocini M, Quiniou G, Garrigue S, Le Mouroux A, Le Métayer P, Clémenty J. Spontaneous initiation of atrial fibrillation by ectopic beats originating in the pulmonary veins. N Engl J Med. 1998; 339(10):659-66. http://dx.doi.org/10.1056/ NEJM199809033391003. PMid:9725923.

Hummel JP, Baher A, Buck B, Fanarjian M, Webber CL Jr, Akar JG. A method for quantifying recurrent patterns of local wavefront direction during atrial fibrillation. Comput Biol Med. 2017; 89:497-504. http://dx.doi.org/10.1016/j. compbiomed.2017.08.027. PMid:28889077.

Jadidi AS, Duncan E, Miyazaki S, Lellouche N, Shah AJ, Forclaz A, Nault I, Wright M, Rivard L, Liu X, Scherr D, Wilton SB,
Sacher F, Derval N, Knecht S, Kim SJ, Hocini M, Narayan S, Haïssaguerre M, Jaïs P. Functional nature of electrogram fractionation demonstrated by left atrial high-density mapping. Circ Arrhythm Electrophysiol. 2012; 5(1):32-42. http://dx.doi. org/10.1161/CIRCEP.111.964197. PMid:22215849.

Jalife J, Berenfeld O, Mansour M. Mother rotors and fibrillatory conduction: a mechanism of atrial fibrillation. Cardiovasc Res. 2002; 54(2):204-16. http://dx.doi.org/10.1016/S00086363(02)00223-7. PMid:12062327.

Kimata A, Yokoyama Y, Aita S, Nakamura H, Higuchi K, Tanaka Y, Nogami A, Hirao K, Aonuma K. Temporally stable frequency mapping using continuous wavelet transform analysis in patients with persistent atrial fibrillation. J Cardiovasc Electrophysiol. 2018; 29(4):514-22. http://dx.doi.org/10.1111/ jce.13440. PMid:29369468.

Konings KT, Kirchhof CJ, Smeets JR, Wellens HJ, Penn OC, Allessie MA. High-density mapping of electrically induced atrial fibrillation in humans. Circulation. 1994; 89(4):1665-80. http://dx.doi.org/10.1161/01.CIR.89.4.1665. PMid:8149534.

Krueger MW, Schulze WH, Rhode KS, Razavi R, Seemann G, Dossel O. Towards personalized clinical in-silico modeling of atrial anatomy and electrophysiology. Med Biol Eng Comput. 2013; 51(11):1251-60. http://dx.doi.org/10.1007/s11517-0120970-0. PMid:23070728.

Marwan N, Carmen Romano M, Thiel M, Kurths J. Recurrence plots for the analysis of complex systems. Phys Rep. 2007; 438(5):237-329. http://dx.doi.org/10.1016/j.physrep.2006.11.001.

Marwan N, Wessel N, Meyerfeldt U, Schirdewan A, Kurths J. Recurrence-plot-based measures of complexity and their application to heart-rate-variability data. Phys Rev E Stat Nonlin Soft Matter Phys. 2002; 66(2):026702. PMid:12241313.

Marwan N. How to avoid potential pitfalls in recurrence plot based data analysis. Int J Bifurcat Chaos. 2011; 21(04):100317. http://dx.doi.org/10.1142/S0218127411029008.

Mindlin GM, Gilmore R. Topological analysis and synthesis of chaotic time series. Physica D. 1992; 58(1):229-42. http:// dx.doi.org/10.1016/0167-2789(92)90111-Y.

Nademanee K, Mckenzie J, Kosar E, Schwab M, Sunsaneewitayakul B, Vasavakul T, Khunnawat C, Ngarmukos T. A new approach for catheter ablation of atrial fibrillation: mapping of the electrophysiologic substrate. J Am Coll Cardiol. 2004; 43(11):2044-53. http://dx.doi.org/10.1016/j.jacc.2003.12.054. PMid: 15172410.

Narayan SM, Krummen DE, Shivkumar K, Clopton P, Rappel WJ, Miller JM. Treatment of atrial fibrillation by the ablation of localized sources: CONFIRM (Conventional Ablation for Atrial Fibrillation With or Without Focal Impulse and Rotor Modulation) trial. J Am Coll Cardiol. 2012; 60(7):628-36. http://dx.doi.org/10.1016/j.jacc.2012.05.022. PMid:22818076.

Navoret N, Jacquir S, Laurent G, Binczak S. Detection of complex fractionated atrial electrograms using recurrence quantification analysis. IEEE Trans Biomed Eng. 2013; 60(7):1975-82. http:// dx.doi.org/10.1109/TBME.2013.2247402. PMid:23428610.

Ravelli F, Faes L, Sandrini L, Gaita F, Antolini R, Scaglione M, Nollo G. Wave similarity mapping shows the spatiotemporal distribution of fibrillatory wave complexity in the human right atrium during paroxysmal and chronic atrial fibrillation. J Cardiovasc Electrophysiol. 2005; 16(10):1071-6. http://dx.doi. org/10.1111/j.1540-8167.2005.50008.x. PMid:16191117. 
Redfearn DP, Simpson CS, Abdollah H, Baranchuk AM. Temporo-spatial stability of complex fractionated atrial electrograms in two distinct and separate episodes of paroxysmal atrial fibrillation. Europace. 2009; 11(11):1440-4. http://dx.doi. org/10.1093/europace/eup287. PMid:19880410.

Rodrigo M, Guillem MS, Climent AM, Pedrón-Torrecilla J, Liberos A, Millet J, Fernández-Avilés F, Atienza F, Berenfeld O. Body surface localization of left and right atrial high-frequency rotors in atrial fibrillation patients: a clinical-computational study. Heart Rhythm. 2014; 11(9):1584-91. http://dx.doi. org/10.1016/j.hrthm.2014.05.013. PMid:24846374.

Rostock T, Rotter M, Sanders P, Takahashi Y, Jais P, Hocini M, Hsu LF, Sacher F, Clémenty J, Haïssaguerre M. High-density activation mapping of fractionated electrograms in the atria of patients with paroxysmal atrial fibrillation. Heart Rhythm. 2006; 3(1):27-34. http://dx.doi.org/10.1016/j.hrthm.2005.09.019. PMid:16399048.

Roux JF, Gojraty S, Bala R, Liu CF, Dixit S, Hutchinson MD, Garcia F, Lin D, Callans DJ, Riley M, Marchlinski F, Gerstenfeld EP. Effect of pulmonary vein isolation on the distribution of complex fractionated electrograms in humans. Heart Rhythm. 2009; 6(2):156-60. http://dx.doi.org/10.1016/j. hrthm.2008.10.046. PMid:19187903.

Roux JF, Gojraty S, Bala R, Liu CF, Hutchinson MD, Dixit S, Callans DJ, Marchlinski F, Gerstenfeld EP. Complex fractionated electrogram distribution and temporal stability in patients undergoing atrial fibrillation ablation. J Cardiovasc Electrophysiol. 2008; 19(8):815-20. http://dx.doi.org/10.1111/ j.1540-8167.2008.01133.x. PMid:18373601.

Salinet J, Schlindwein FS, Stafford P, Almeida TP, Li X, Vanheusden FJ, Guillem MS, Ng GA. Propagation of meandering rotors surrounded by areas of high dominant frequency in persistent atrial fibrillation. Heart Rhythm. 2017; 14(9):1269-78. http:// dx.doi.org/10.1016/j.hrthm.2017.04.031. PMid:28438722.

Salinet JL, Tuan JH, Sandilands AJ, Stafford PJ, Schlindwein FS, $\mathrm{Ng}$ GA. Distinctive patterns of dominant frequency trajectory behavior in drug-refractory persistent atrial fibrillation: preliminary characterization of spatiotemporal instability. J Cardiovasc Electrophysiol. 2013; 25(4):371-9. http://dx.doi. org/10.1111/jce.12331. PMid:24806529.

Schilling C. Analysis of atrial electrograms [dissertation]. Karlsruhe: Karlsruhe Institute of Technology; 2012.

Schilling RJ, Peters NS, Davies W. Simultaneous endocardial mapping in the human left ventricle using a noncontact catheter: comparison of contact and reconstructed electrograms during sinus rhythm. Circulation. 1998; 98(9):887-98. http://dx.doi. org/10.1161/01.CIR.98.9.887. PMid:9738644.

Schmitt C, Zrenner B, Schneider M, Karch M, Ndrepepa G, Deisenhofer I, Weyerbrock S, Schreieck J, Schömig A. Clinical experience with a novel multielectrode basket catheter in right atrial tachycardias. Circulation. 1999; 99(18):2414-22. http:// dx.doi.org/10.1161/01.CIR.99.18.2414. PMid:10318663.

Soriano DC, Suyama R, Attux R. Blind extraction of chaotic sources from white gaussian noise based on a measure of determinism. Berlin: Springer; 2009. p. 122-9. http://dx.doi. org/10.1007/978-3-642-00599-2_16.

Soriano DC, Suyama R, Attux R. Blind extraction of chaotic sources from mixtures with stochastic signals based on recurrence quantification analysis. Dig Sig Proc. 2011; 21(3):417-26. http://dx.doi.org/10.1016/j.dsp.2010.12.003.

Stevenson WG, Soejima K. Recording techniques for clinical electrophysiology. J Cardiovasc Electrophysiol. 2005; 16(9):101722. http://dx.doi.org/10.1111/j.1540-8167.2005.50155.x. PMid:16174026.

Stiles MK, Brooks AG, John B, Wilson L, Kuklik P, Dimitri H, Lau DH, Roberts-Thomson RL, Mackenzie L, Willoughby S, Young GD, Sanders P. The effect of electrogram duration on quantification of complex fractionated atrial electrograms and dominant frequency. J Cardiovasc Electrophysiol. 2008; 19(3):252-8. http://dx.doi.org/10.1111/j.1540-8167.2007.01034.x. PMid:18302697.

Tang M, Chang CQ, Fung PC, Chau KT, Chan FHY. An improved method for discriminating ECG signals using typical nonlinear dynamic parameters and recurrence quantification analysis in cardiac disease therapy. In: IEEE Engineering in Medicine and Biology 27th Annual Conference; 2006 Jan 17-18; Shanghai. USA: IEEE; 2006. p. 2459-62.

Tsai WC, Wang JH, Lin YJ, Tsao HM, Chang SL, Lo LW, Hu YF, Chang CJ, Tang WH, Huang SY, Suenari K, Tuan TC, Chen SA. Consistency of the automatic algorithm in detecting complex fractionated electrograms using an electroanatomical navigation system. Pacing Clin Electrophysiol. 2012; 35(8):980-9. http:// dx.doi.org/10.1111/j.1540-8159.2012.03444.x. PMid:22816370.

Tuan J, Jeilan M, Kundu S, Nicolson W, Chung I, Stafford PJ, Ng GA. Regional fractionation and dominant frequency in persistent atrial fibrillation: effects of left atrial ablation and evidence of spatial relationship. Europace. 2011; 13(11):1550-6. http://dx.doi.org/10.1093/europace/eur174. PMid:21712282.

Verma A, Wulffhart Z, Beardsall M, Whaley B, Hill C, Khaykin Y. Spatial and temporal stability of complex fractionated electrograms in patients with persistent atrial fibrillation over longer time periods: relationship to local electrogram cycle length. Heart Rhythm. 2008; 5(8):1127-33. http://dx.doi. org/10.1016/j.hrthm.2008.04.027. PMid:18675223.

Webber CL Jr, Zbilut JP. Dynamical assessment of physiological systems and states using recurrence plot strategies. J Appl Physiol. 1994; 76(2):965-73. http://dx.doi.org/10.1152/ jappl.1994.76.2.965. PMid:8175612.

Webber CL Jr, Zbilut JP. Recurrence quantifications: feature extractions from recurrence plots. Int J Bifurcat Chaos. 2007; 17(10):3467-75. http://dx.doi.org/10.1142/S0218127407019226.

Yang H. Multiscale recurrence quantification analysis of spatial cardiac vectorcardiogram signals. IEEE Trans Biomed Eng. 2011; 58(2):339-47. http://dx.doi.org/10.1109/TBME.2010.2063704. PMid:20693104.

Zaman JA, Narayan SM. Ablation of atrial fibrillation: How can less be more? Circ Arrhythm Electrophysiol. 2015; 8(6):1303-5. http://dx.doi.org/10.1161/CIRCEP.115.003495. PMid:26671931.

Zbilut JP, Thomasson N, Webber CL. Recurrence quantification analysis as a tool for nonlinear exploration of nonstationary cardiac signals. Med Eng Phys. 2002; 24(1):53-60. http:// dx.doi.org/10.1016/S1350-4533(01)00112-6. PMid:11891140. 